\title{
1 Thermally and optically stimulated radiative processes in Eu and Y co-doped $\mathrm{LiCaAlF}_{6}$ crystal
}

18

\author{
Kentaro Fukudaa), Takayuki Yanagidab), Yutaka Fujimotob) \\ a Tokuyama Corporation, 1-1 Mikage-cho, Shunan-shi, Yamaguchi, 745-8648 Japan \\ b Kyushu Institute of Technology, 2-4 Hibikino, Wakamatsu, Kitakyushu, Fukuoka, 808-0196, Japan
}

\begin{abstract}
Yttrium co-doping was attempted to enhance dosimeter performance of Eu doped $\mathrm{LiCaAlF}_{6}$ crystal. Eu doped and Eu, $\mathrm{Y}$ co-doped $\mathrm{LiCaAlF}_{6}$ were prepared by the micro-pulling-down technique, and their dosimeter characteristics such as optically stimulated luminescence (OSL) and thermally stimulated luminescence (TSL) were investigated. By yttrium co-doping, emission intensities of OSL and TSL were enhanced by some orders of magnitude. In contrast, scintillation characteristics of yttrium co-doped crystal such as intensity of prompt luminescence induced by X-ray and light yield under neutron irradiation were degraded.
\end{abstract}

Keywords: Scintillator; OSL; TSL; dosimeter; $\mathrm{LiCaAlF}_{6}$; neutron

${ }^{*}{ }_{1}$ Corresponding author. Present address: Tokuyama Corporation, 1-1 Mikage-cho, Shunan-shi, Yamaguchi, 745-8648 Japan

Tel.: +8122 217 5822; fax: +81222175102.

E-mail address: ken-fukuda@ tokuyama.co.jp (Kentaro Fukuda) 


\section{Introduction}

Luminescent materials have played an important role in radiation detectors to convert invisible ionizing radiation to visible photons. The most famous one of such luminescent materials is a scintillator which immediately emits scintillation photons when they absorb the energy of ionizing radiation via the energy migration process from host to emission centers [1]. Scintillation detectors are widely used as main parts of large instruments in medical [2], security [3], well-logging [4], and high energy physics [5]. On the other hand, storage phosphors have attracted much attention for small radiation detector devices, especially in personal dosimeters. In dosimeter applications, optically stimulated luminescence (OSL) [6], thermally stimulated luminescence (TSL) [7], and radiophotoluminescence (RPL) [8] are used to evaluate dose from sub mGy to a few Gy. Unlike scintillators, defective materials are favorable for dosimeter since the origin of OSL and TSL are trapped careers in defect levels. Though scintillators and dosimeter materials have same physical processes from absorption of the energy of ionizing radiation to generation of thousands of secondary electrons, their final emission processes are different.

Recently, we proposed the hypothesis that scintillation efficiency and OSL/TSL yield should be complementary, for a given energy deposition. When the energy of ionizing radiation is absorbed in materials, some parts of the absorbed energy are released by a prompt emission (scintillation). Fraction for this scintillation is only 10 20\% of the absorbed energy even in excellent scintillator and dominant part of energy is used for non-scintillation processes. Historically, remaining 80-90\% of the energy has been considered to become a thermal loss. In our assumption, some parts of remaining energies are stored in the material and they can be released by stimulation (OSL or TSL). In other cases, remaining parts of energy are converted to thermal energies which are also used in calorimeter for radiation detection. In $\mathrm{Ce}$ doped $\mathrm{CaF}_{2}$ material system, we experimentally confirmed the complementary relation between scintillation and OSL [9]. The aim of this work is to examine our hypothesis in other material systems.

In the present work, we investigated OSL and TSL properties of Eu-doped and $\mathrm{Eu}, \mathrm{Y}$ co-doped $\mathrm{LiCaAlF}_{6}$. In this test, nominal dopant concentrations were $0.5 \%$. Eu-doped $\mathrm{LiCaAlF}_{6}$ was developed as a scintillator for thermal neutron detectors [10-11] and characterized by high scintillation light yield under thermal neutron irradiation. Recently, we investigated dosimeter properties of Czochralski grown Eu-doped $\mathrm{LiCaAlF}_{6}$ [12]. Eu-doped $\mathrm{LiCaAlF}_{6}$ showed detectable signals in TSL and quite weak signal in OSL [12]. In order to enhance TSL and OSL properties of Eu-doped $\mathrm{LiCaAlF}_{6}, \mathrm{Y}^{3+}$ ion was introduced into Eu-doped $\mathrm{LiCaAlF}_{6}$. Since rare-earth ions are considered to 
51 substitute $\mathrm{Ca}^{2+}, \mathrm{Y}^{3+}$ co-doping would create some defects due to a charge imbalance [13]. In addition, $\mathrm{Y}^{3+}$ ion is an

ideal co-dopant in this study since it is non-luminescent ion. In this time, sample crystals were prepared by the micro-pulling-down ( $\mu$-PD) technique in Tokuyama Corporation. Figure 1 exhibits cut and polished samples for this work. Visibly, no significant difference was observed.

\section{Experimental procedures}

At first, to evaluate influence of Y co-doping on scintillation responses, X-ray induced radioluminescence spectra at room temperature were corrected. The setup was described previously [14]. Supplied bias voltage and tube current for $\mathrm{X}$-ray generator was $40 \mathrm{kV}$ and $5 \mathrm{~mA}$ respectively. The spectra were measured by a monochromator (Andor SR163) equipped with CCD (Andor DU920P) via an optical fiber in 10 seconds of exposure time. Then, scintillation decay profiles were evaluated by pulse X-ray equipped afterglow characterization system in the fast mode [15]. In this system, wavelength was not resolved and the timing resolution was around $1 \mathrm{~ns}$ limited by the transition time of photomultiplier tube (R7400 Hamamatsu). ${ }^{252} \mathrm{Cf}$ induced pulse height spectra were evaluated by using PMT (Hamamatsu R7600U-200) and subsequent electronics [16]. ${ }^{252} \mathrm{Cf}$ was enclosed by polyethylene blocks to thermalize fast neutrons. Sample was wrapped with a reflector made of Teflon tape and coupled with PMT by using optical grease (OKEN 6262A). Once scintillation photons were detected by PMT, signal was fed into preamplifier (ORTEC 113) and shaping amplifier (ORTEC 572) with $6 \mu$ s shaping time.

OSL and TSL properties were examined by using X-ray generator as an exposure source. Dose values were set from $10 \mathrm{mGy}$ to $1 \mathrm{~Gy}$ and dose were calibrated by the ionizing chamber. OSL was evaluated by Hamamatsu Quantaurus- $\tau$ in spectrometer mode. This instrument equipped stable LED light source and stability performance was better than conventional lamp-type light sources. In OSL, stimulation wavelength was set to $470 \mathrm{~nm}$, an optimal stimulation wavelength within various LEDs (from 405 to $630 \mathrm{~nm}$ ). Fading characteristics in the first 5 minutes were also evaluated by JASCO FP8600 spectrofluorometer equipped with Xe lamp and intensity correction function. TSL glow curves from 50 to $450{ }^{\circ} \mathrm{C}$ under heating rate of $1{ }^{\circ} \mathrm{C} / \mathrm{sec}$ were obtained by TL2000 [17]. The irradiated dose was set from $0.1 \mathrm{mGy}$ to $1 \mathrm{~Gy}$. 


\section{Experimental results and discussion}

$\mathrm{X}$-ray induced radioluminescence spectra of $\mathrm{LiCaAlF}_{6}$ crystals are shown in figure 2. Intense emission peaking at $375 \mathrm{~nm}$ due to $\mathrm{Eu}^{2+} 5 \mathrm{~d}-4 \mathrm{f}$ transition was observed and weak emission bands around $585 \mathrm{~nm}$ due to $\mathrm{Eu}^{3+} 4 \mathrm{f}-4 \mathrm{f}$ transition were also detected. Although the emission intensity of the former one of Y co-doped sample decreased about half of that of $\mathrm{Eu}$ singly doped sample, the $4 \mathrm{f}-4 \mathrm{f}$ emission resulted in same level. Similar example was found in photoluminescence of $\mathrm{Eu}$ and $\mathrm{Y}$ co-doped $\mathrm{Ca}_{2} \mathrm{P}_{2} \mathrm{O}_{7}$ where rare earth ions would substitute $\mathrm{Ca}^{2+}$ site [18]. This phenomenon could be understood as follows. By Y-codoping, charge balance is broken due to a charge imbalance of $\mathrm{Y}^{3+}$ and $\mathrm{Ca}^{2+}$. Generally, rare-earth elements substitute $\mathrm{Ca}^{2+}$ site in $\mathrm{LiCaAlF}_{6}$ host. To compensate this charge imbalance, some defects are created in Y co-doped sample and these defects trap careers (secondary electrons). Then, scintillation yield degraded in Y co-doped sample and, on the other hand, OSL and TSL intensities were improved as described later since these storage-type emissions were originated from defects. This is a good example of our hypothesis of the complementary relation of scintillation and OSL/TSL.

Figure 3 represents X-ray induced scintillation decay time profiles of present samples. Though a primary component with few $\mu$ s decay due to $\mathrm{Eu}^{2+} 5 \mathrm{~d}-4 \mathrm{f}$ transition was similar in two samples, background levels of $\mathrm{Y}$ co-doped sample was approximately ten times higher than that of Eu singly doped one. The High background was mainly due to a very slow component and in this case there were two possibilities for the origin. One was $\mathrm{Eu}^{3+} 4 \mathrm{f}-4 \mathrm{f}$ emission of ms order decay constant and the other was radiation induced afterglow. Because emission intensities at $585 \mathrm{~nm}$ of two samples in radioluminescence were similar levels, the origin of the slow component would be attributed to afterglow. In general, afterglow is described as a phosphorescence due to the thermal release of the carriers from several traps, and deemed to TSL around room temperature.

Figure 4 demonstrates ${ }^{252} \mathrm{Cf}$ neutron irradiated pulse height spectra of $\mathrm{LiCaAlF}_{6}$ samples. Thermal neutron peak channel of Y co-doped sample was around $60 \%$ of that of Eu singly doped one. Observed results were consistent with X-ray induced radioluminescence spectra. Scintillation properties such as radioluminescence, scintillation decay time, and pulse height of $\mathrm{Y}$ co-doped sample degraded compared to Eu singly doped LiCaAlF 6 . To our knowledge, it is a common sense that unnecessary co-dopant makes scintillation properties worse.

OSL spectra stimulated by $470 \mathrm{~nm}$ LED after 1 Gy X-ray exposure are demonstrated in figure 5. Obviously, Y co-doped sample exhibited ten times higher OSL intensity than Eu singly doped one. In previous report, we could not 
detect OSL from Czochralski grown Eu-doped $\mathrm{LiCaAlF}_{6}[12]$ while we could observe OSL in this time. Since Eu singly doped $\mathrm{LiCaAlF}_{6}$ crystal in this study was grown by the $\mu$-PD technique and it was generally known that crystals grown by $\mu$-PD were defective than those by Czochralski. Figure 6 exemplifies the relation between irradiated dose and OSL intensity. From $10 \mathrm{mGy}$ to $1 \mathrm{~Gy}$, Y co-doped sample showed a linear response and we could not observe OSL in Eu singly doped $\mathrm{LiCaAlF}_{6}$ below $100 \mathrm{mGy}$ exposure. In figure 7, OSL fading time profiles of two samples are shown. By Y co-doping, fading became faster than Eu singly doped sample and we cannot explain so far since fading characteristics of OSL were not yet studied enough except for some commercial materials (e.g., C-doped $\mathrm{Al}_{2} \mathrm{O}_{3}[6]$ ).

TSL glow curves after 10 mGy X-ray exposure are depicted in figure 8. Some glow peaks appeared in $100-250{ }^{\circ} \mathrm{C}$. Interestingly, glow curves of these $\mu$-PD grown samples differed from those of previously reported Czochraski grown samples [12]. New glow peak appeared only in $\mu$-PD grown samples around $100{ }^{\circ} \mathrm{C}$ and it revealed the unique defect creation depending on growth techniques. By Y co-doping, TSL intensity became stronger by two orders of magnitude and TSL results were consistent with scintillation decay time profiles (Fig. 3). In figure 9, TSL response functions against the dose from $0.1 \mathrm{mGy}$ to 1 Gy showed good linearity both in Eu singly and Y co-doped samples.

Consequently, the aim of present work to enhance dosimeter properties of Eu-doped $\mathrm{LiCaAlF}_{6}$ was achieved by $\mathrm{Y}^{3+}$ co-doping along our assumption that scintillation and OSL/TSL were in a complementally relation. Such a complementary relationship was confirmed only in Ce-doped $\mathrm{CaF}_{2}$ and Eu-doped $\mathrm{LiCaAlF}_{6}$ material systems so far. We would like to investigate other materials systems to confirm our hypothesis.

\section{Conclusion and Future Prospects}

$\mathrm{Eu} 0.5 \%$ singly and $\mathrm{Eu}$ and $\mathrm{Y} 0.5 \%$ doubly doped $\mathrm{LiCaAlF}_{6}$ crystals were fabricated by Tokuyama Corporation using the $\mu$-PD technique. By $\mathrm{Y}$ co-doping, scintillation properties including $\mathrm{X}$ - ray induced radioluminescence, scintillation decay time, and ${ }^{252} \mathrm{Cf}$ neutron induced scintillation light yield degraded. On the other hand, TSL and OSL were largely improved by Y co-doping.

\section{Acknowledgements}

This work was mainly supported by a Grant in Aid for Scientific Research (A)-26249147 from the Ministry 
of Education, Culture, Sports, Science and Technology of the Japanese government (MEXT) and partially by JST

A-step. Partial assistance from Nippon Sheet Glass Foundation for Materials Science and Engineering, Tokuyama

Science foundation, Iketani Science and Technology Foundation, Hitachi Metals Materials Science Foundation,

Mazda Foundation, JFE 21st century Foundation, and The Asahi Glass Foundation, the Cooperative Research

Project of Research Institute of Electronics, Shizuoka University and Collaborative Research Program of Institute

for Chemical Research, Kyoto University (2014-31) are also gratefully acknowledged.

\section{References}

[1] T. Yanagida, Opt. Mater., 351987 (2013).

[2] T. Yanagida, A. Yoshikawa, Y. Yokota, K. Kamada, Y. Usuki, S. Yamamoto, M. Miyake, M. Baba, K. Sasaki, and M. Ito, IEEE. Nucl. Trans. Sci., 571492 (2010).

[3] D. Totsuka, T. Yanagida, K. Fukuda, N. Kawaguchi, Y. Fujimoto, Y. Yokota, A. Yoshikawa, Nucl. Instrum. Methods A, 659399 (2011).

[4] T. Yanagida, Y. Fujimoto, S. Kurosawa, K. Kamada, H. Takahashi, Y. Fukazawa, M. Nikl, V. Chani, Jpn. J. Appl. Phys., 52, 076401 (2013).

[5] T. Ito, M. Kokubun, T. Takashima, T.Yanagida, S. Hirakuri, R. Miyawaki, H. Takahashi, K. Makishima, T. Tanaka, K. Nakazawa, T. Takahashi, T. Honda, IEEE Trans. Nucl. Sci. 53, 2983 (2006).

[6] E. G. Yukihara, S. W. S. McKeever, Optically Stimulated Luminescence: Fundamentals and Applications, Wiley (2011).

[7] S. W.S. McKeever, Thermoluminescence of Solids, Cambridge University Press (1985).

[8] Y. Miyamoto, T. Ohno, Y. Takei, H. Nanto, T. Kurobori, T. Yanagida, A. Yoshikawa, Y. Nagashima, T. Yamamoto, Rad. Meas., 5572 (2013).

[9] T. Yanagida, Y. Fujimoto, K. Watanabe, K. Fukuda, N. Kawaguchi, Y. Miyamoto, H. Nanto, Rad. Meas., in press, 10.1016/j.radmeas.2014.03.020 (2014).

[10] T. Yanagida, N. Kawaguchi, Y. Fujimoto, K. Fukuda, Y. Yokota, A. Yamazaki, K. Watanabe, J. Pejchal, A. Uritani, T. Iguchi, A. Yoshikawa, Opt. Mater., 33, 1243 (2011).

[11] T. Yanagida, A. Yamaji, N. Kawaguchi, Y. Fujimoto, K. Fukuda, S. Kurosawa, A. Yamazaki, K. Watanabe, Y. Futami, Y. Yokota, A. Uritani, T. Iguchi, A. Yoshikawa, M. Nikl, Appl. Phys. Express 4106401 (2011).

[12] T. Yanagida, Y. Fujimoto, K. Watanabe, K. Fukuda, Rad. Meas., in press 10.1016/j.radmeas.2014.02.021 (2014).

[13] J. B. Amaral, M. E.G. Valerio, M. A. C. dos Santos, R. A. Jackson, Nucl. Instrum. Methods B, 218232 (2004).

[14] T. Yanagida, K. Kamada, Y. Fujimoto, H. Yagi, T. Yanagitani, Opt. Mat.,35 2480-2485 (2013).

[15] T. Yanagida, Y. Fujimoto, T. Ito, K. Uchiyama, K. Mori, Appl. Phys. Exp., 7062401 (2014).

[16] T. Yanagida, Y. Fujimoto, K. Fukuda, V. Chani, Nucl. Instrum. Methods A, 72958 (2013).

[17] T. Yanagida, Y. Fujimoto, N. Kawaguchi, S. Yanagida, J. Ceram. Soc. Jpn., 121989 (2013).

[18] R. Pang, C. Li, S. Zhang, Q. Su, Materials Chemistry and Physics, 113215 (2009). 
165

166

167

168

169

170

171

172

173

174

175

176

177

178

179

180

181

182

183

184

Figure caption

Figure 1. Picture of Eu-doped (left) and Y co-doped (right) $\mathrm{LiCaAlF}_{6}$.

Figure 2. X-ray induced radioluminescence spectra of Eu singly doped and Y co-doped samples.

Figure 3. X-ray induced scintillation decay time profiles of Eu singly doped and Y co-doped samples.

Figure 4. $\quad{ }^{252} \mathrm{Cf}$ neutron induced pulse height spectra of Eu singly doped and $\mathrm{Y}$ co-doped samples.

Figure 5. OSL emission spectra of Eu singly doped and Y co-doped samples after 1 Gy exposure.

Figure 6. OSL intensities of Eu singly doped and Y co-doped samples plotted against the dose (mGy).

Figure 7. OSL fading time profiles of Eu singly doped and Y co-doped samples after 10 Gy exposure.

Figure 8. TSL glow curves of Eu singly doped and Y co-doped samples after 10 mGy exposure.

Figure 9. TSL intensities of Eu singly doped and Y co-doped samples plotted against the dose (mGy). 


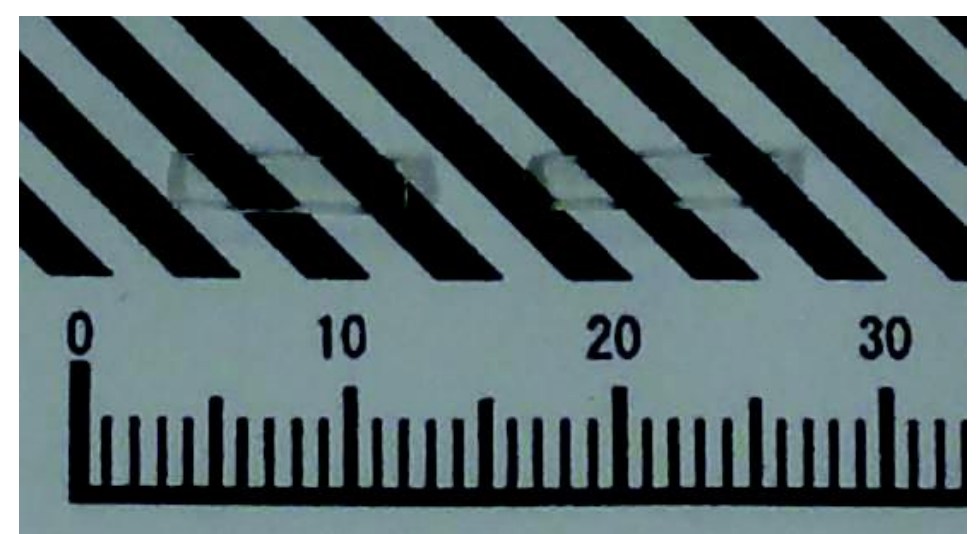

186 Figure 1. Eu-doped (left) and Y co-doped (right) LiCaAlF . 


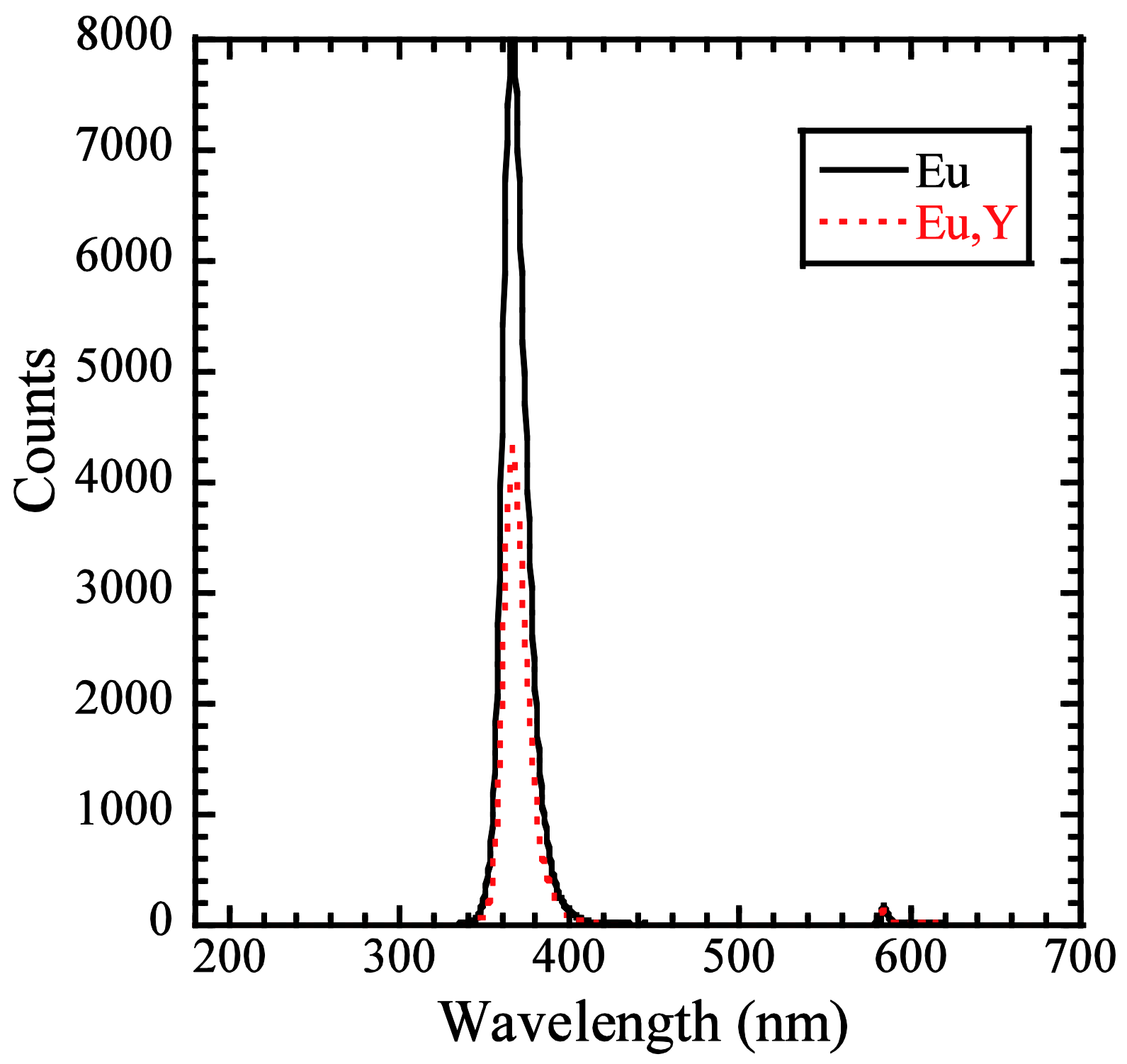

189 Figure 2. X-ray induced radioluminescence spectra of Eu singly doped and Y co-doped samples. 


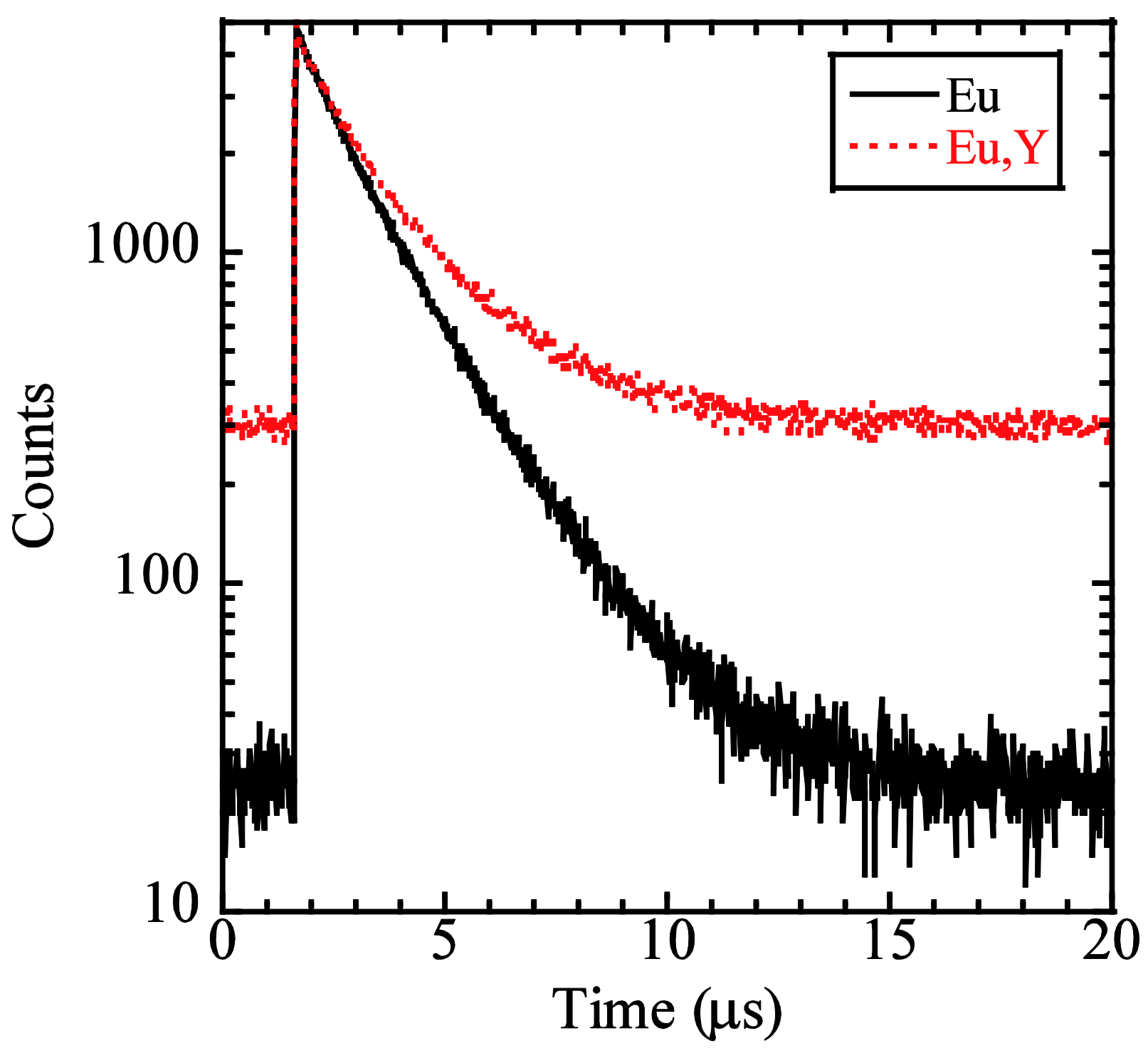

192 Figure 3. X-ray induced scintillation decay time profiles of Eu singly doped and Y co-doped samples. 
194

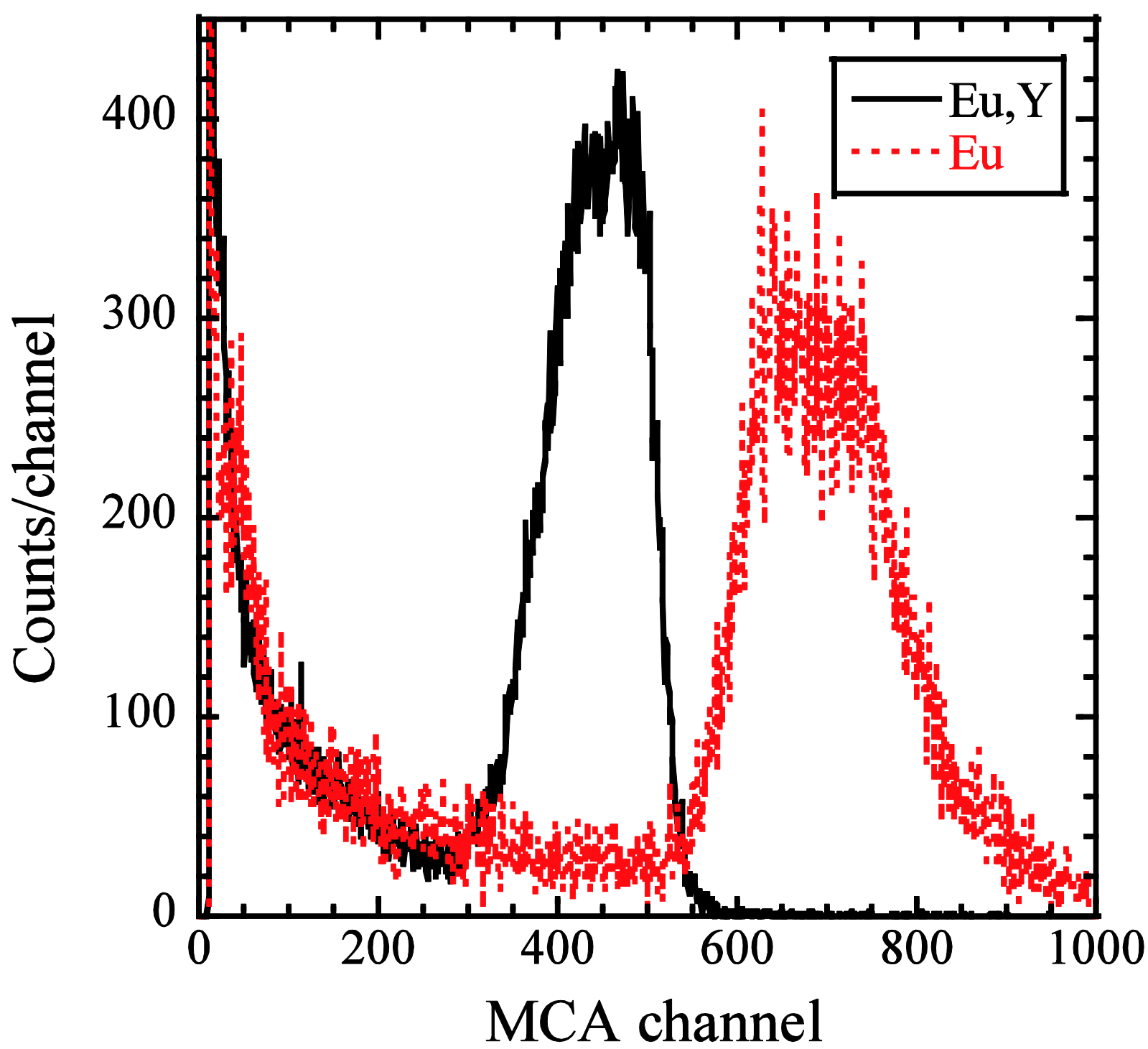

195 Figure 4. ${ }^{252} \mathrm{Cf}$ neutron induced pulse height spectra of Eu singly doped and Y co-doped samples. 


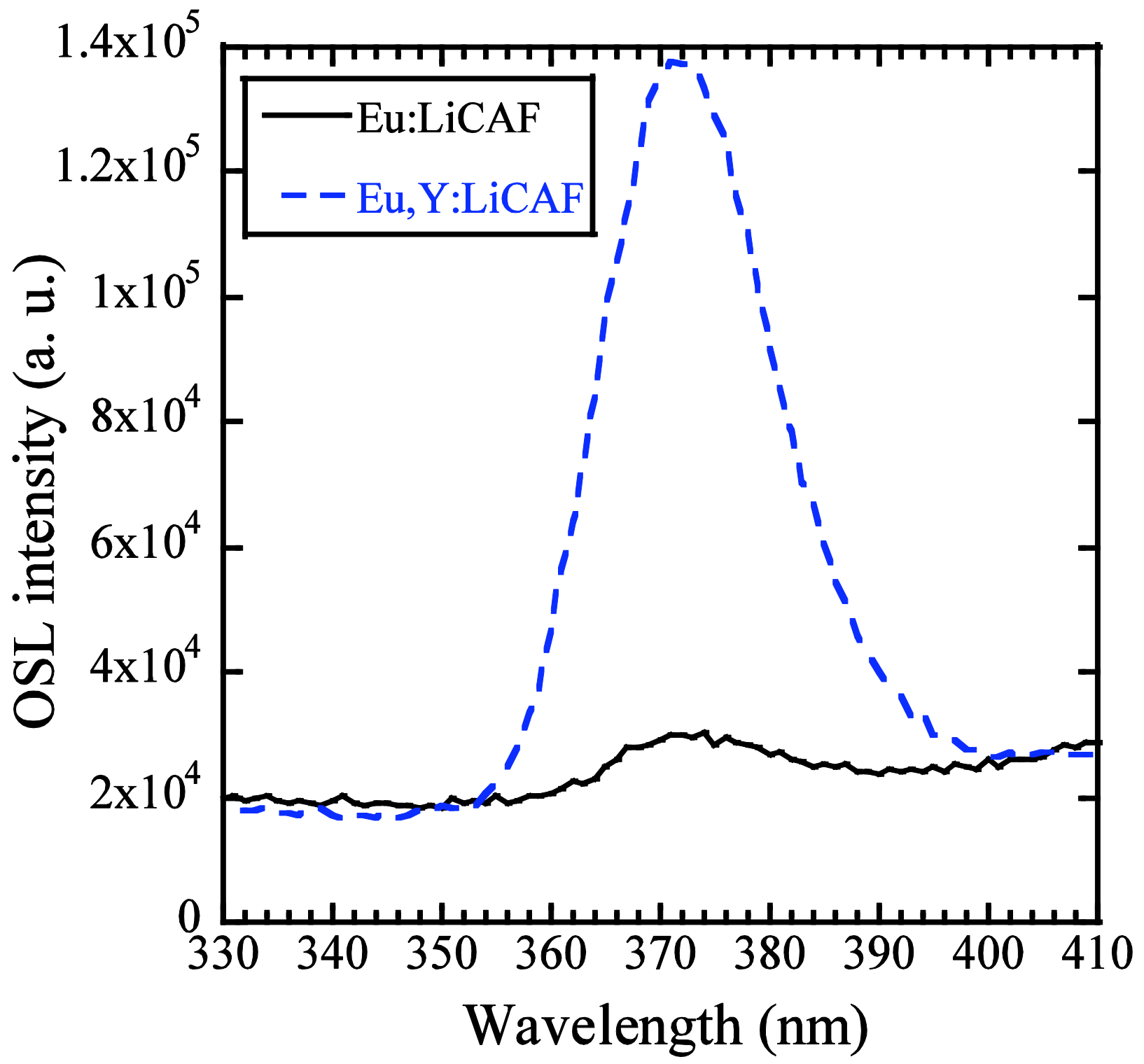

198 Figure 5. OSL emission spectra of Eu singly doped and Y co-doped samples after 1 Gy exposure. 


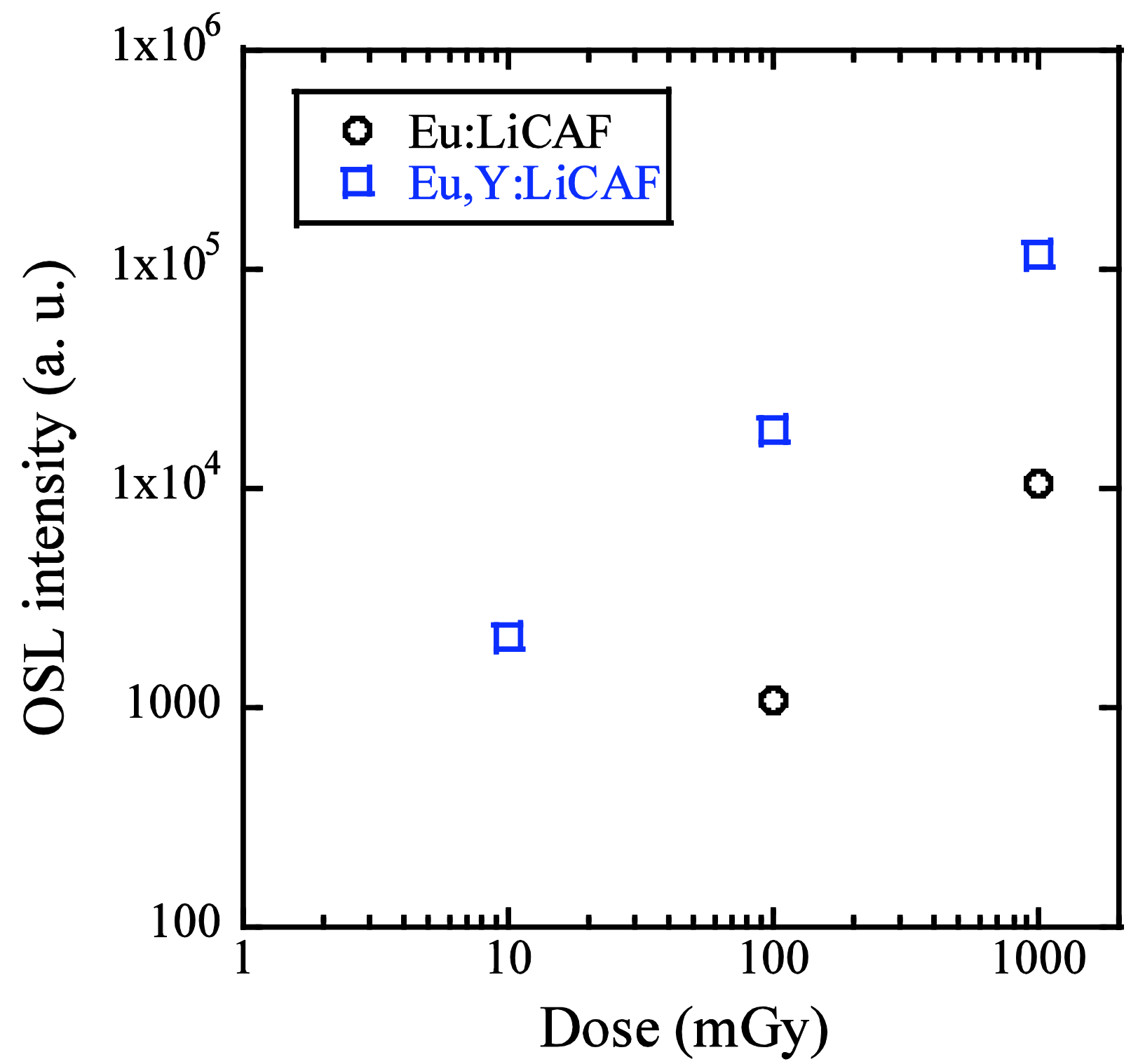

201 Figure 6. OSL intensities of Eu singly doped and Y co-doped samples plotted against the dose (mGy). 


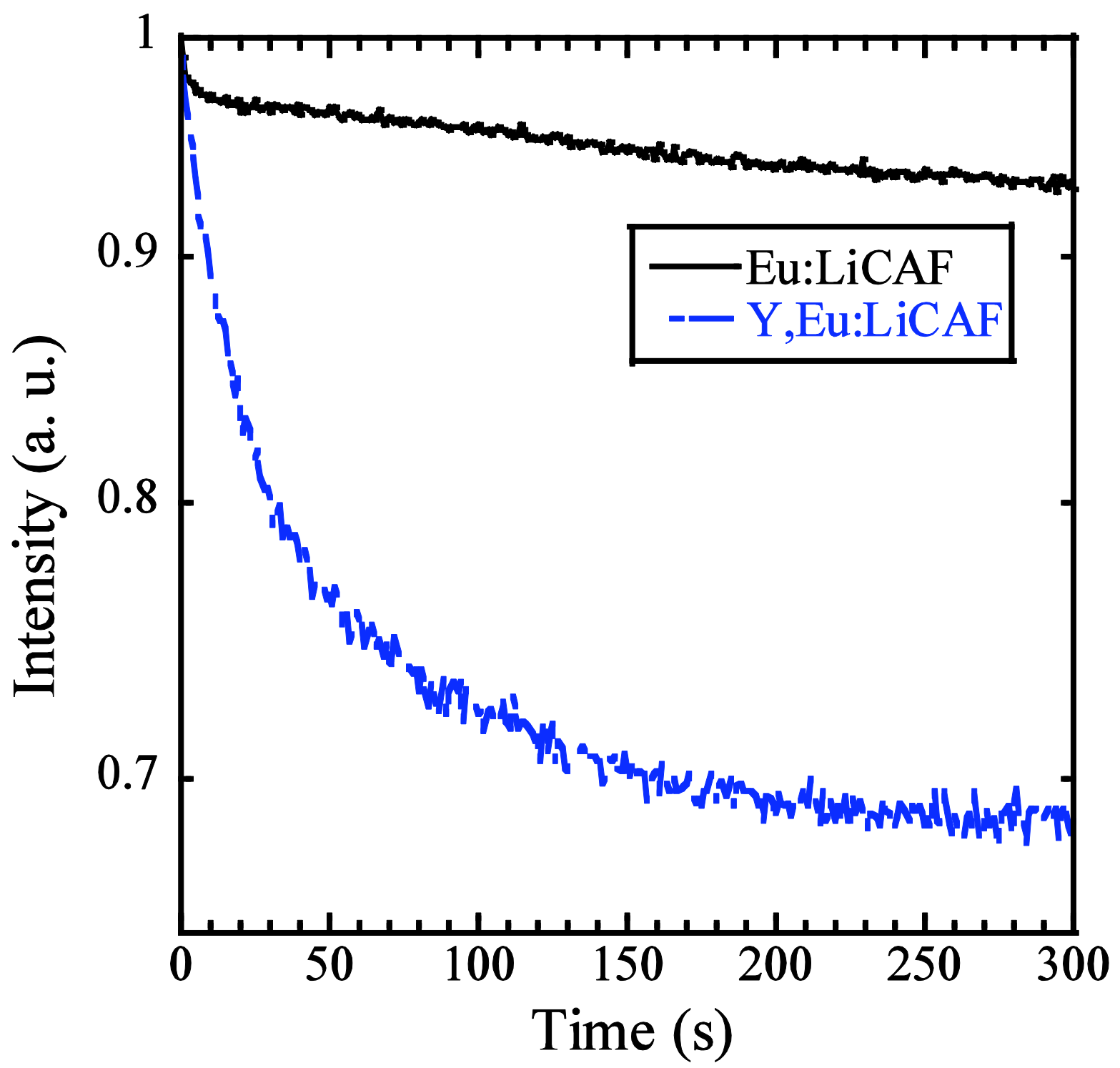

204 Figure 7. OSL fading time profiles of Eu singly doped and Y co-doped samples after 10 Gy exposure. 


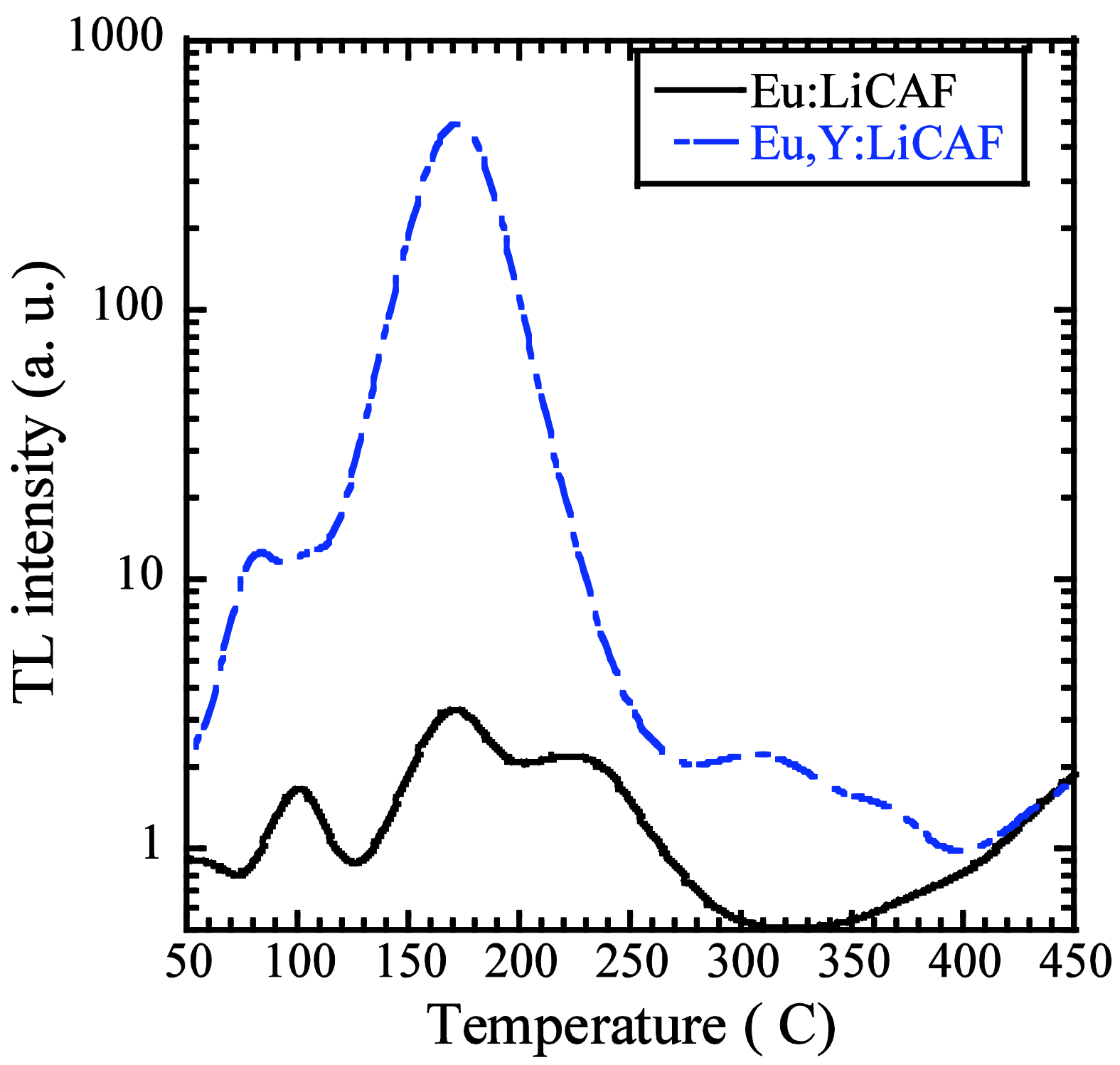

207 Figure 8. TSL glow curves of Eu singly doped and Y co-doped samples after 10 mGy exposure. 


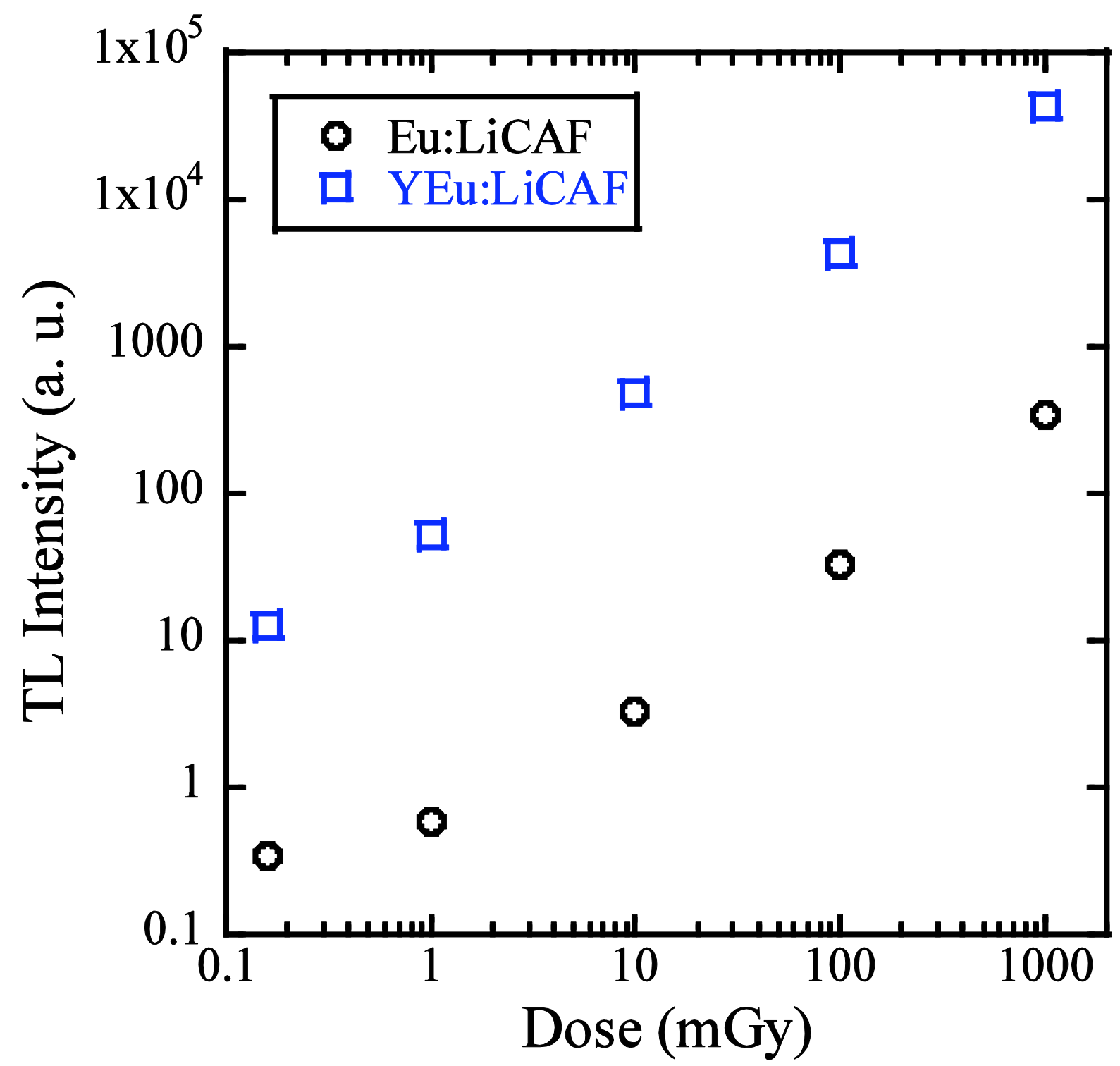

210 Figure 9. TSL intensities of Eu singly doped and Y co-doped samples plotted against the dose (mGy). 